\title{
The effect of mild hypothermia on Nogo-A and neurological function in the brain after cardio-pulmonary resuscitation in rats.
}

\author{
Jia-Li Li ${ }^{1}, \mathrm{Yu} \mathrm{Cao}{ }^{2}, \mathrm{Hu} \mathrm{Nie}^{2 *}$ \\ ${ }^{1}$ Department of Emergency, the $2^{\text {nd }}$ Affiliated Hospital of Chengdu Medical College Nuclear Industry 416 Hospital, \\ Chengdu, PR China \\ ${ }^{2}$ Department of Emergency, West China Hospital, Sichuan University, Chengdu, PR China
}

\begin{abstract}
The aim of the current study was to investigate dynamic changes in brain Nogo-A protein in rats, and the effects of mild hypothermia therapy on its expression after Cardio-Pulmonary Resuscitation (CPR). Western-blotting and neurological scoring of 45 rats subjected to cardiac arrest and CPR were performed to investigate the expression of Nogo-A protein in the hippocampus and cortex $6 \mathrm{~h}, 12 \mathrm{~h}, 24 \mathrm{~h}$, $48 \mathrm{~h}$, and $72 \mathrm{~h}$ after restoration of spontaneous circulation (ROSC). Nogo-A expression levels gradually increased from $6 \mathrm{~h}$ after CPR in the brain. In the hippocampus and cortex, Nogo-A exhibited a unimodal waveform-first it increased, but then it decreased. It peaked at $24 \mathrm{~h}$ in the hippocampus, and at $48 \mathrm{~h}$ in the cortex. The expression of Nogo-A in the mild hypothermia group was significantly lower at $12 \mathrm{~h}(\mathrm{p}<\mathbf{0 . 0 5})$. Mild hypothermia can reduce the expression of Nogo-A protein in the hippocampus and cortex after CPR, which may be one of the mechanisms that play a role in cerebral protection.
\end{abstract}

Keywords: Sudden cardiac arrest, Restoration of spontaneous circulation (ROSC), Mild therapeutic hypothermia (MTH), Nogo-A protein.

Accepted on December 11, 2017

\section{Introduction}

Nogo-A protein is a growth axon inhibitory molecule associated myelin, and it is widely distributed in oligodendrocytes and neurons in the Central Nervous System (CNS). Nogo-A is one of the most important inhibitors of nerve regeneration after central nerve injury in mammals $[1,2]$. As well as being a strong axon growth inhibitory factor in the CNS, both in vitro and in vivo experiments have shown that it has close relationships with the regeneration of CNS neural axons [3]. Ischemia in the CNS and the inhibition of nerve cells are related to axon inhibition of Nogo-A [4]. Nogo-A expression has been investigated in various conditions including cerebral ischemia, spinal cord injury, and injury of the optic nerve, and it has been reported that Nogo-A expression is significantly increased at $25 \mathrm{~d}$ after arterial occlusion [5].

Mild Therapeutic Hypothermia (MTH) is currently the only proven effective method of brain protection that can improve survival rates and reduce neurologic sequelae [6]. The different degrees of therapeutic hypothermia include profound therapeutic hypothermia, moderate therapeutic hypothermia, and MTH. Profound therapeutic hypothermia and moderate therapeutic hypothermia have been applied in neurosurgery and cardiac surgery, and were associated with cerebral protection. However, the mechanism of cerebral protection associated with MTH is unclear. When hypothermia is too low, the patient may experience serious complications including blood coagulation dysfunction and arrhythmia [7]. However, if hypothermia only reduces the temperature by $2-3^{\circ} \mathrm{C}$, cerebral protection is achieved and none of the complications associated with profound therapeutic hypothermia are induced. Therefore, therapeutic hypothermia has attracted interest, and the benefits of MTH were acknowledged in Cardiopulmonary Resuscitation (CPR) guidelines in 2010. A recent study showed that with every hypothermic reduction of $1{ }^{\circ} \mathrm{C}$, the cerebral metabolic rate reduced by $6-10 \%$ [8]. Cerebral protection is not only associated with a reduced cerebral metabolic rate, but also with the slowing of a series of injurious reactions including the generation of free radicals, mitochondrial and cell membrane damage, and calcium ion pump dysfunction. Thus, hypothermia can protect against cerebral ischemic and reperfusion injury [8].

Numerous studies have shown that MTH can regulate myocardial tissue blood flow, reduce the myocardial oxygen metabolism rate, and maintain protection of cell signal transduction [9-11]. However, few studies have focused on the expression of Nogo-A protein in the brain after CPR. The current study investigated the characteristics of Nogo-A protein levels at different time-points associated with acute brain injury after CPR, and the effects of MTH on Nogo-A protein expression. 


\section{Materials and Methods}

\section{Animals}

Male Sprague-Dawley (SD) rats (age 12-14 w, weight $370 \pm 30$ g) were provided by Sichuan (certification number: SCXK (chuan) 2014-24), and had been bred in the Laboratory Animal Unit of the West China Hospital of Sichuan University. Rats were adapted for $1 \mathrm{w}$, they had unrestricted access to food and water, and there were 5 rats in each cage (room temperature 20 $\pm 2^{\circ} \mathrm{C}$, relative humidity $40-60 \%$ ). The rats were fasted for 12 $\mathrm{h}$ prior to experimentation, but they had unrestricted access to water. This study was carried out in strict accordance with the recommendations in the Guide for the Care and Use of Laboratory Animals of the National Institutes of Health. The animal use protocol has been reviewed and approved by the Institutional Animal Care and Use Committee (IACUC) of Sichuan University.

\section{Establishment of restoration of spontaneous circulation animal model}

Rats were initially intraperitoneally injected with $0.3 \%$ pentobarbital $45 \mathrm{mg} / \mathrm{kg}$, and a dose of $15 \mathrm{mg} / \mathrm{kg}$ was used to maintain anesthesia. The anaesthetized rats were fixed in a supine position, and mechanically ventilated via a rodent ventilator. II-lead electrocardiograms were recorded in the upper limbs and the left lower limb. The right arteria cruralis was separated, and two $4^{\#}$ stitches were made after the artery to ligate it distally, and a $24 \mathrm{G}$ arterial puncture needle was inserted proximally in conjunction with heparin sodium salt. The right femoral vein was separated and a $22 \mathrm{G}$ venous indwelling needle was inserted in conjunction with heparin sodium salt, and this was the route used to inject drugs and liquid. Heart rate, heart rhythm, systolic pressure, diastolic pressure, and Mean Arterial Pressure (MAP), were continuously monitored. The chest area was shaved, and defibrillating electrodes were inserted in the apex area and at the bottom of the heart to connect a Heart Stan XL manual defibrillator. Bipolar pacemaker electrode wires were inserted into the esophagus via the oral cavity, and the placement was deemed successful if neither flustering nor exasperation occurred.

Continuous thin current communication at a frequency of 50 $\mathrm{Hz}$ and $10 \mathrm{~V}$ was used to achieve electrophotoluminescence of the epicardium via the esophagus, which contributed to ventricular fibrillation. After electrophotoluminescence had been initiated, and breathing machine was stopped and ventilation was monitored. After $3 \mathrm{~min}$, electrophotoluminescence was stopped, and sudden cardiac arrest was maintained for 6 min when the average arterial pressure was lower than $20 \mathrm{mmHg}$. CPR was then performed in accordance with the Utstein model [12]. Chest compressions were performed, and with reference to observed changes in electrocardiogram waveform, $5 \mathrm{~J} / \mathrm{kg}$ direct current single-phase wave was used to achieve electric shock defibrillation once per min if ventricular rhythm was detected. If autonomous cardiac rhythm was not recovered within 3 min, 1:10,000 epinephrine solution $(20 \mu \mathrm{g} / \mathrm{kg})$ was injected intravenously once every 3 min until Restoration of Spontaneous Circulation (ROSC) occurred or the experiment was stopped.

\section{ROSC parameters}

ROSC was deemed to have occurred if autonomous cardiac rhythm was recovered with a MAP $\geq 50 \mathrm{mmHg}$ and was maintained for $>10 \mathrm{~min}$. If CPR was applied for $20 \mathrm{~min}$ but ROSC was not achieved, or ROSC was not maintained for 10 min, the animal was deemed to be dead and was thereafter excluded from the study. The breathing machine was removed from rats with ROSC, and they were continuously monitored for $1 \mathrm{~h}$. Rats were returned to their cages after they had recovered from anesthesia and exhibited powerful spontaneous breathing.

\section{Grouping and treatment}

Fifteen male SD rats (age 12-14 w, weight $370 \pm 30 \mathrm{~g}$ ) were randomly divided into 3 groups of $n=5$ using a random number table, a sham group (S), a ROSC group (R), and a MTH group (M). An additional 30 male SD rats (12-14 w, weight $370 \pm 30$ g) were randomly divided into a sham group $(\mathrm{S}, \mathrm{n}=5)$ and a ROSC group $(R, n=25)$. In this $R$ group of $n=25$, subgroups of 5 rats were executed at $6 \mathrm{~h}, 12 \mathrm{~h}, 24 \mathrm{~h}, 48 \mathrm{~h}$, and $72 \mathrm{~h}$ after ROSC recovery. In the $\mathrm{S}$ group, rats were subjected to endotracheal intubation and femoral arteriovenous insertion, and they were not subjected to electrical stimulation to induce cardiac arrest.

\section{General condition and assessment of neurological function}

Heart rate and MAP were recorded in each group before ventricular fibrillation and after ROSC. Neurological Deficit Score (NDS) was used to assess neurologic impairment at $24 \mathrm{~h}$ after ROSC. The NDS reflects 7 components of neurological function; whole behavior, brainstem function, muscular tension, feeling, sports, behavior, and epileptic seizure. The maximum total score is 80 , where 80 is defined as "normal", and 0 indicates brain death (Table 1) [13].

\section{Statistical analysis}

Data that were normally distributed were analysed using the mean \pm standard deviation, and Student's t-test was used to assess differences between two groups. Data that were not normally distributed were analysed using the median and extremum values, and the rank sum test was used to assess differences. Analysis of variance was used to assess differences between groups, and multi-factor analysis of variance was used to assess differences in multiple factors between groups. 
The effect of mild hypothermia on Nogo-A and neurological function in the brain after cardio-pulmonary resuscitation in rats

$\mathrm{p}<0.05$ was considered statistically significant, and all the

statistical analyses were performed using SPSS 20.0 software.

Table 1. Neurological Deficit Score (NDS) standard scale.

\begin{tabular}{|c|c|}
\hline Classification & Standards \\
\hline \multirow[t]{3}{*}{ Whole behavior (19) } & Normal consciousness, 10 ; stupor, 5 ; coma, 0 \\
\hline & Autonomous opening eyes after rouse, 3 ; opening eyes with ache, 0 ; don't open, 0 \\
\hline & Dupnea, 6; abnormal breathe, 3; deficiency, 0 \\
\hline \multirow[t]{7}{*}{ Brainstem function (21) } & Smell exists, 3; deficiency, 0 \\
\hline & Vision exists, 3; deficiency, 0 \\
\hline & Pupillary light reflex exists, 3 ; deficiency, 0 \\
\hline & Corneal reflex exists, 3 ; deficiency, 0 \\
\hline & Intimidation reflection exists, 3 ; deficiency, 0 \\
\hline & Tentacles reflection exists, 3 ; deficiency, 0 \\
\hline & Swallowing reflex exists, 3 ; deficiency, 0 \\
\hline \multirow[t]{2}{*}{ Muscular tension (6) } & Normal muscular tension (left), 3; stiffness/subtract, 1 ; no exercise/paralysis, 0 \\
\hline & Normal muscular tension (right), 3; stiffness/subtract, 1 ; no exercise/paralysis, 0 \\
\hline \multirow[t]{2}{*}{ Feeling (6) } & Pain (left), acute withdrawal, 3; bluntness/abnormality, 1; deficiency, 0 \\
\hline & Pain (right), acute withdrawal, 3; bluntness/abnormality, 1; deficiency, 0 \\
\hline \multirow[t]{2}{*}{ Sports (6) } & Normal gait coordination, 3; abnormality, 1; deficiency, 0 \\
\hline & Normal beam balance, 3 ; abnormality, 1 ; deficiency, 0 \\
\hline \multirow[t]{4}{*}{ Behavior (12) } & Normal return to the right way, 3 ; abnormality, 1 ; deficiency, 0 \\
\hline & Normal Hasten to test, 3; abnormality, 1; deficiency, 0 \\
\hline & Normal vision localization, 3; abnormality, 1; deficiency, 0 \\
\hline & Normal turning experiment, 3 ; abnormality, 1 ; deficiency, 0 \\
\hline Epileptic seizure (10) & No convulsion, 10; local convulsion, 5; global convulsion, 0 \\
\hline
\end{tabular}

The total score of 80 indicates normal, and score of 0 indicates brain death.

\section{Results}

\section{Effect of MTH on Nogo-A protein expression and neurological function in the cerebral cortex and hippocampus}

Western blotting indicated that compared to the $\mathrm{S}$ group, NogoA protein expression was significantly increased in the $M$ and $\mathrm{R}$ groups $(\mathrm{p}<0.05)$. Compared to the $\mathrm{R}$ group, Nogo-A expression was significantly reduced in the $M$ group $(p<0.05)$ (Figure 1). Compared to the $\mathrm{R}$ group, changes in heart rate and MAP in the other groups were smaller and no significant differences were detected $(\mathrm{p}>0.05)$, but neural functional recovery was superior to the $\mathrm{R}$ group $(\mathrm{p}<0.05)$ (Table 2$)$.
A

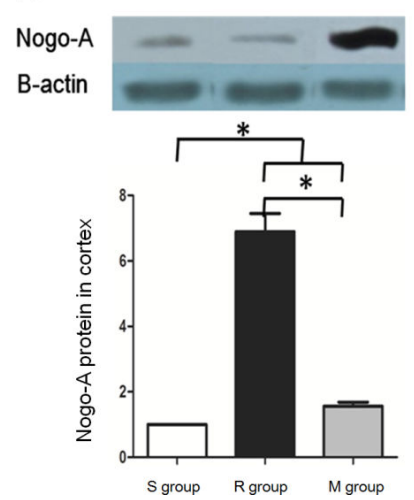

B

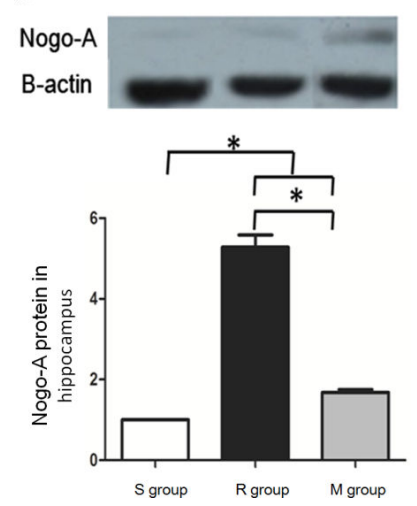

Figure 1. Effect of Mild Therapeutic Hypothermia (MTH) on expression of Nogo-A protein in cortex (A) and hippocampus (B) in rats. 
Table 2. Effect of Mild Therapeutic Hypothermia (MTH) on HR, MAP and neurological function in rats.

\begin{tabular}{llllll}
\hline & & S group & R group & M group & P \\
\hline \multirow{2}{*}{ HR (beat/min) } & Base line & $396.40 \pm 8.23$ & $402.00 \pm 8.22$ & $396.80 \pm 13.81$ \\
\cline { 2 - 5 } & After ROSC & & $349.40 \pm 39.1$ & $297.60 \pm 33.49$ \\
\hline MAP (mmHg) & Base line & $126.80 \pm 12.17$ & $138.00 \pm 7.17$ & $70.00 \pm 9.11$ \\
\cline { 2 - 5 } & After ROSC & & $82.4 \pm 7.70$ & 80 & 0.067 \\
\hline NDS (score, median (extremum)) & Base line & 80 & 80 & $69(68,72)$ & 0.046 \\
\cline { 2 - 5 } & After ROSC & & $66(65,70)$ & & \\
\hline
\end{tabular}

\section{Changes in Nogo-A protein expression in the cerebral cortex and hippocampus at different time-points after ROSC}

Brain tissues were collected at $6 \mathrm{~h}, 12 \mathrm{~h}, 24 \mathrm{~h}, 48 \mathrm{~h}$, and $72 \mathrm{~h}$ after ROSC, and Nogo-A expression levels in the cerebral cortex and hippocampus were assessed via western blotting. In the cerebral cortex, Nogo-A protein expression peaked at $24 \mathrm{~h}$ after ROSC, then gradually reduced, and stabilized at $72 \mathrm{~h}$. At every time-point, Nogo-A expression levels in these $\mathrm{R}$ subgroups were higher than they were in the $S$ group $(p<0.05)$. In the hippocampus, Nogo-A expression peaked at $48 \mathrm{~h}$ after ROSC and then gradually reduced. At every time-point, NogoA expression levels in these R subgroups were higher than they were in the $\mathrm{S}$ group $(\mathrm{p}<0.05)$ (Figure 2).

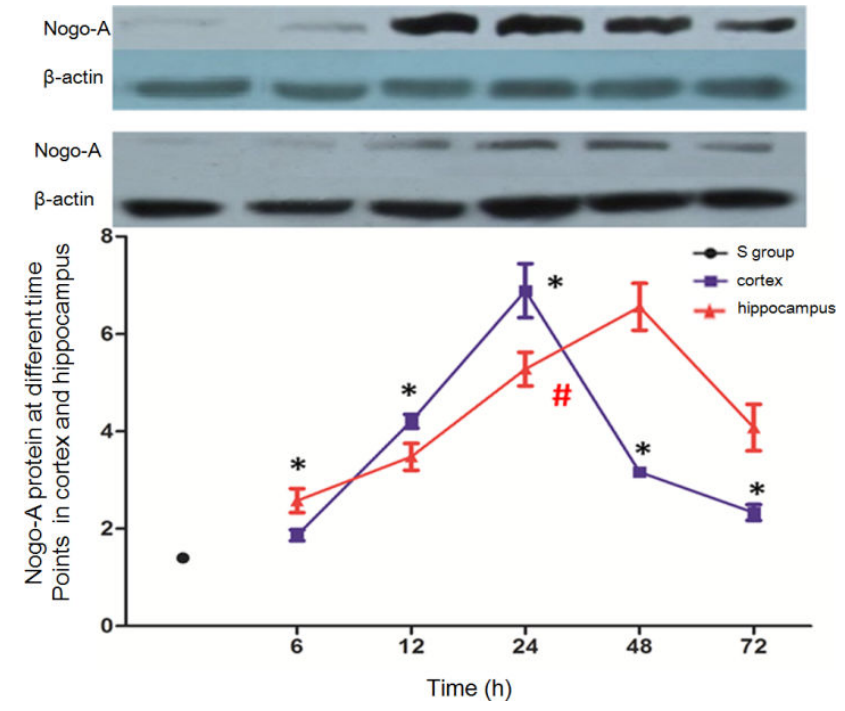

Figure 2. Change of Nogo-A protein at different time points in cortex and hippocampus after ROSC. Note: ${ }^{*}$ indicates statistical difference between different time points $(p<0.05)$, \#indicates that expression tendency of NOGO-A protein is statistical difference between cortex and hippocampus.

\section{Discussion}

Many inhibitory factors are important causes of limited nerve fiber regeneration after CPR, which can lead to the CNS damage. Regeneration is mainly influenced by the functional regeneration of axons, and it is difficult to achieve effective rehabilitation if these inhibitory factors are not addressed $[14,15]$. Nogo-A protein is a transmembrane protein with an inhibitory effect on axon regeneration, and it is a strong inhibitor of nerve fiber regeneration. Previous Nogo-A studies have mainly focused on apoplexy, hypoxic-ischemic encephalopathy, and spinal cord injury. MTH can reportedly inhibit Nogo-A protein expression in the brain in many rat models, and it can accelerate neurons shaft breaking bud and increase dendrite branching, thus contributing to neural functional recovery [14].

Previous studies have shown that inhibition of Nogo-A can relieve cerebral injury, increase the regeneration of damaged nerve cells, and accelerate neural functional recovery. The molecular mechanisms of the cerebral protection achieved via the inhibition of Nogo-A mainly include increased axon regeneration and vicarious sprouting, increased myelin and myelin sheath capacity, increased synaptic plasticity with regard to building new loops, and facilitation of the migration of certain cells that play roles in injured parts of the brain including astrocytes, microglial cells, and macrophages/ inflammatory cells [11,16-18]. In the current study, Nogo-A expression levels in the cortex and hippocampus were significantly increased in the $\mathrm{R}$ group compared to before anabiosis. Nogo-A is increased in the brain after injury, and MTH can inhibit the over-expression of Nogo-A. These findings suggest that MTH inhibited increased Nogo-A expression in the R group, though Nogo-A expression was still higher than it was in the control group. Specifically, MTH indirectly inhibited Nogo-A expression by affecting other brain injury-related factors, although further investigation is required to clarify the mechanisms involved.

In the current study, Nogo-A expression exhibited time distribution specificity in the cerebral cortex and hippocampus after ROSC. Nogo-A initially increased, then reached a peak, then reduced. These variations are similar to what has been reported in other animal models [19], and Du et al. [8] reported that Nogo-A expression increased in lateral cortex and striatum ischemia after cerebral ischemic mode in an ischemic stroke model, then reached the peak, then gradually declined. With regard to the peak expression of Nogo-A, the main mechanism may relate to the stimulation of nerve cells under the stressed state. Particularly, oligodendroglia cells can generate and secrete more Nogo-A protein. Nogo-A will reduce when brain 
tissue undergoes ischemia, degeneration, and necrosis, and synthesis of many proteins and neurotransmitters will be reduced. Regulated changes in Nogo-A are consistent with the progression of patients after ROSC, and $50 \%$ of patients may die within $24 \mathrm{~h}$ after ROSC. When general condition and cardiac function stabilize, damage in brain tissue is gradually reduced, but severe damage can occur within 1-3 d [20]. Therefore, we speculate that Nogo-A expression levels are positively correlated with the severity of brain damage, because Nogo-A is widely distributed in oligodendrocytes and neurons, and it is an axon growth inhibiting factor associated with myelin. After Nogo-A binds to its receptor, NgR, it can activate the Rho GTPase signal transduction pathway, leading to growth cone collapse, and the inhibition of loop formation and dendritic branches and synapses. These events can further inhibit nerve regeneration after damage [21], and therefore the over-expression of Nogo-A can influence recovery from cerebral injury. Notably, a small quantity of Nogo-A is detected in normal brain, which may relate to the role of NogoA in contributing to axonal transport and synapse formation. The process can maintain stability of the cortex and hippocampus neuron circuits, and these regions have a certain amount of structural plasticity [22,23].

Taken together, the results of the current study suggest that Nogo-A protein contributes to early-stage brain injury after ROSC, and it is maintained for at least $72 \mathrm{~h}$. In the clinic, early detection of serum Nogo-A can be used to estimate the degree of severity and prognosis of early ROSC (24 h, not continuous), which will contribute to strengthening interventions, accelerating recovery of neurological function, and improving survival. However, brain nerve dysfunction after cardiac arrest involves many mechanisms, and Nogo-A is only one of these. Additional studies should be performed to further clarify the complex mechanisms involved in brain nerve dysfunction.

\section{Conflicts of Interest}

All of the authors declare that they have no conflicts of interest regarding this paper.

\section{Acknowledgments}

This work was supported by grants from Science-technology Support Plan Projects of SCST (No. 2013SZ0079).

\section{References}

1. Chen MS, Huber AB, van der Haar ME, Frank M, Schnell L, Spillmann AA, Christ F, Schwab ME. Nogo-A is a myelin-associated neurite outgrowth inhibitor and an antigen for monoclonal antibody IN-1. Nature 2000; 403 : 434-439.

2. Wälchli T, Pernet V, Weinmann O, Shiu JY, GuzikKornacka A, Decrey G, Yuksel D, Schneider H, Vogel J, Ingber DE, Vogel V, Frei K, Schwab ME. Nogo-A is a negative regulator of CNS angiogenesis. Proc Natl Acad Sci USA 2013; 110: 1943-1952.
3. Tsai SY, Markus TM, Andrews EM, Cheatwood JL, Emerick AJ, Mir AK, Schwab ME, Kartje GL. Intrathecal treatment with anti-Nogo-A antibody improves functional recovery in adult rats after stroke. Exp Brain Res 2007; 182: 409-423.

4. Walmsley AR, Mir AK. Targeting the Nogo-A signalling pathway to promote recovery following acute CNS injury. Curr Pharm Des 2007; 13: 2470-2484.

5. Jian YE, Wang ZG, Zhu PF. Expressive varieties of NogoA mRNA in injured optic nerves. Chinese J Ocular Fundus Dis 2003; 19: 247-249.

6. Jiang S, He X, Wang J, Zhou G, Zhang M, Ba L, Yang J, Zhao X. Therapeutic mild hypothermia improves early outcomes in rabbits subjected to traumatic uncontrolled hemorrhagic shock. J Surg Res 2013; 179: 145-152.

7. Lewinter MM, Popper J, McNabb M, Nyland L, Bell SB, Granzier H. Extensible behavior of titin in the miniswine left ventricle. Circulation 2010; 121: 768-774.

8. Bergman R, Braber A, Adriaanse MA, van Vugt R, Tjan DH, van Zanten AR. Haemodynamic consequences of mild therapeutic hypothermia after cardiac arrest. Eur J Anaesthesiol 2010; 27: 383-387.

9. Behringer W, Arrich J, Holzer M, Sterz F. Out-of-hospital therapeutic hypothermia in cardiac arrest victims. Scand J Trauma Resusc Emerg Med 2009; 17: 52.

10. Miyauchi T, Wei EP, Povlishock JT. Evidence for the therapeutic efficacy of either mild hypothermia or oxygen radical scavengers after repetitive mild traumatic brain injury. J Neurotrauma 2014; 31: 773-781.

11. Cruces P, Erranz B, Donoso A, Carvajal C, Salomon T, Torres MF, Díaz F. Mild hypothermia increases pulmonary anti-inflammatory response during protective mechanical ventilation in a piglet model of acute lung injury. Paediatr Anaesth 2013; 23: 1069-1077.

12. Idris AH, Becker LB, Ornato JP, Hedges JR, Bircher NG, Chandra NC, Cummins RO, Dick W, Ebmeyer U, Halperin HR, Hazinski MF, Kerber RE, Kern KB, Safar P, Steen PA, Swindle MM, Tsitlik JE, von Planta I, von Planta M, Wears RL, Weil MH. Utstein-style guidelines for uniform reporting of laboratory CPR research. A statement for healthcare professionals from a task force of the American Heart Association, the American College of Emergency Physicians, the American College of Cardiology, the European Resuscitation Council, the Heart and Stroke Foundation of Canada, the Institute of Critical Care Medicine, the Safar Center for Resuscitation Research, and the Society for Academic Emergency Medicine. Writing Group. Circulation 1996; 94: 2324-2336.

13. Geocadin RG, Ghodadra R, Kimura T, Lei H, Sherman DL, Hanley DF, Thakor NV. A novel quantitative EEG injury measure of global cerebral ischemia. Clin Neurophysiol 2000; 111: 1779-1787.

14. Malik RA. Early detection of nerve damage and repair in diabetic neuropathy. Nat Clin Pract Neurol 2008; 4: 646-647. 
15. Malik RA, Kallinikos P, Abbott CA, van Schie CH, Morgan P, Efron N, Boulton AJ. Corneal confocal microscopy: a non-invasive surrogate of nerve fibre damage and repair in diabetic patients. Diabetologia 2003; 46: 683-688.

16. Kowalik R, Szczerba E, Koltowski L, Grabowski M, Chojnacka K, Golecki W, Holubek A, Opolski G. Cardiac arrest survivors treated with or without mild therapeutic hypothermia: performance status and quality of life assessment. Scand J Trauma Resusc Emerg Med 2014; 22: 76.

17. Magaldi M, Fontanals J, Moreno J, Ruiz A, Nicolas JM, Bosch X. Survival and neurological outcome in out-ofhospital cardiac arrests due to shockable rhythms treated with mild therapeutic hypothermia. Med Intensiva 2014; 38: 541-549.

18. Grazi M, Rubino M, Milazzo V, Cabiati A. Mild therapeutic hypothermia for the treatment of cardiac arrest and acute myocardial infarction. Recenti Prog Med 2014; 105: 68-72.

19. Yasuda Y, Shimoda T, Uno K, Tateishi N, Furuya S, Tsuchihashi Y, Kawai Y, Naruse S, Fujita S. Temporal and sequential changes of glial cells and cytokine expression during neuronal degeneration after transient global ischemia in rats. $\mathrm{J}$ Neuroinflammation 2011; 8: 1-10.
20. Mychasiuk R, Hehar H, Ma I, Kolb B, Esser MJ. The development of lasting impairments: a mild pediatric brain injury alters gene expression, dendritic morphology, and synaptic connectivity in the prefrontal cortex of rats. Neuroscience 2015; 288: 145-155.

21. Schawkat K, Di Santo S, Seiler S, Ducray AD, Widmer HR. Loss of Nogo-A-expressing neurons in a rat model of Parkinsons disease. Neuroscience 2015; 288: 59-72.

22. Weber JP, Andrasfalvy BK, Polito M, Mago A, Ujfalussy BB, Makara JK. Location-dependent synaptic plasticity rules by dendritic spine cooperativity. Nat Commun 2016; 7: 11380 .

23. ODonnell C, Nolan MF, van Rossum MC. Dendritic spine dynamics regulate the long-term stability of synaptic plasticity. J Neurosci 2011; 31: 16142-16156.

\section{${ }^{*}$ Correspondence to}

$\mathrm{Hu}$ Nie

Department of Emergency

West China Hospital of Sichuan University

PR China 